\title{
Sustainability as a Trigger for Innovation!
}

\author{
Fabrice Gallou*
}

SCS Senior Industrial Science Award 2019

\begin{abstract}
About a decade ago, prompted by regulatory pressure, we at Novartis entered the field of micellar catalysis. We were fortunate to discover some enabling techniques that rapidly allowed for application and deep impact of the technology within our development portfolio. In parallel, we endeavored to push the boundaries of science, building a powerful toolbox of chemistry, and gaining in the understanding of such systems. Of particular importance is the compartmentalization effect that needs to be well understood and mastered to access all the benefits of the technology. The following review article will illustrate our journey more specifically for SuzukiMiyaura cross-couplings, with some detours that will further highlight the impact of the technology.
\end{abstract}

Keywords: Catalysis $\cdot$ Micelles $\cdot$ Nano-particles $\cdot$ Surfactant $\cdot$ Sustainability

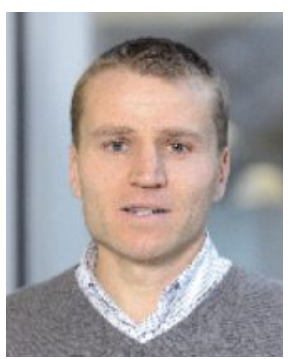

Fabrice Gallou received his $\mathrm{PhD}$ from The Ohio State University (2001) in the field of natural products total synthesis. He then joined Chemical Development at Boehringer Ingelheim, USA, working as a process chemist responsible for route scouting and supply of early phase programs. He subsequently moved in 2006 to the Chemical Development group at Novartis, Switzerland, as a process development chemist, and became in 2008 responsible for global scientific activities, overseeing development and implementation of practical and economical chemical processes for large scale production of APIs. His research interests rely in the research and development of sustainable synthetic methodologies intended for large scale implementation. He has published more than 150 peer-reviewed papers, book chapters, and patents, and won multiple awards, most recently the 2019 Swiss Chemical Society Senior Industrial Science Award, and the 2019 Yves Chauvin Award from the French Chemical Society.

\section{Introduction}

There is not a single day without alarming news about climate change, or the unsustainable pace at which the world is growing. It is our responsibility, of each of us scientists especially, and collectively within our respective organizations, to change the culture, to offer disruptive options to dramatically revert the unsustainable practices, and to inspire these courageous changes. Around the end of 2010, we at Novartis actively started to tackle the environmental issues rightly raised by the legislation. Of paramount importance to us was the improper usage of toxic substances, and more specifically of the highly common polar aprotic solvents flagged to be reprotoxic. The REACH legislation and its Substance of Very High Concern arm especially prompted us to act in a strategic way. ${ }^{[1]}$ About a dozen projects of various levels of ambition and scope were started, either internally, or externally with chemical suppliers and vendors, along with academic collaborators. We investigated the potential of supercritical media, ${ }^{[2]}$ evaluated various ampho- teric solvents in an unbiased manner (collaboration Fribourg), promoted the development of more desirable alternatives, ${ }^{[3]}$ and more generally, as will be explained in the following, developed a toolbox of chemistry in bulk water. For this latter approach, we were obviously strengthening our arsenal of biocatalytic tools, and complemented this aspect with a de novo toolbox of surfactant-mediated chemistry.

\section{Discussion}

While chemistry on water had been documented for decades, ${ }^{[4]}$ we were fortunate to evaluate its latest development introduced by Professor Lipshutz ${ }^{[5]}$ around 2006-2008 as early as 2010. The spectacular selectivities and yields resulting from the mild micellar conditions sparked our interest. Such systems were also perfectly designed, with high permitted daily exposure, and suitable biodegradability of a green-by-design vitamin E-derived TPGS750-M surfactant especially, ${ }^{[6]}$ making it a remarkable fit to pharma applications. Early extensive understanding and evaluation of the scope of the technology had indeed demonstrated that the approach could advantageously lead to the substitution of reprotoxic polar aprotic solvents such as NMP, DMF, or DMAc, in such frequently encountered transformations as nucleophilic aromatic substitutions, amide bond formation, or various kind of crosscouplings (unpublished, 2010-2011), something that we later on more thoroughly evaluated and reported. ${ }^{[7]}$ Not only could an important switch to more desirable solvents be envisioned, ${ }^{[8]}$ but also significant environmental, productivity and cost savings could be achieved. With the field entirely novel at the industrial scale, we had a large number of development activities to complete such as to establish a supply chain, to complete the environmental study and waste management activities... We therefore decided to focus our attention on TPGS-750-M as we saw in it a very versatile surfactant. The benign-by-design TPGS-750-M surfactant, when used above its critical micelle concentration (CMC), in our case at $2 \mathrm{wt} \%$ in water, rearranges itself in a supramolecular way into round micelles, based on the hydrophobicity concept, the amphiphiles 'protecting' themselves from the aqueous environment by forming thermodynamically more stable micelles of round shape in this case (Fig. 1). 
Fig. 1. Overview of micellar phenomenon.

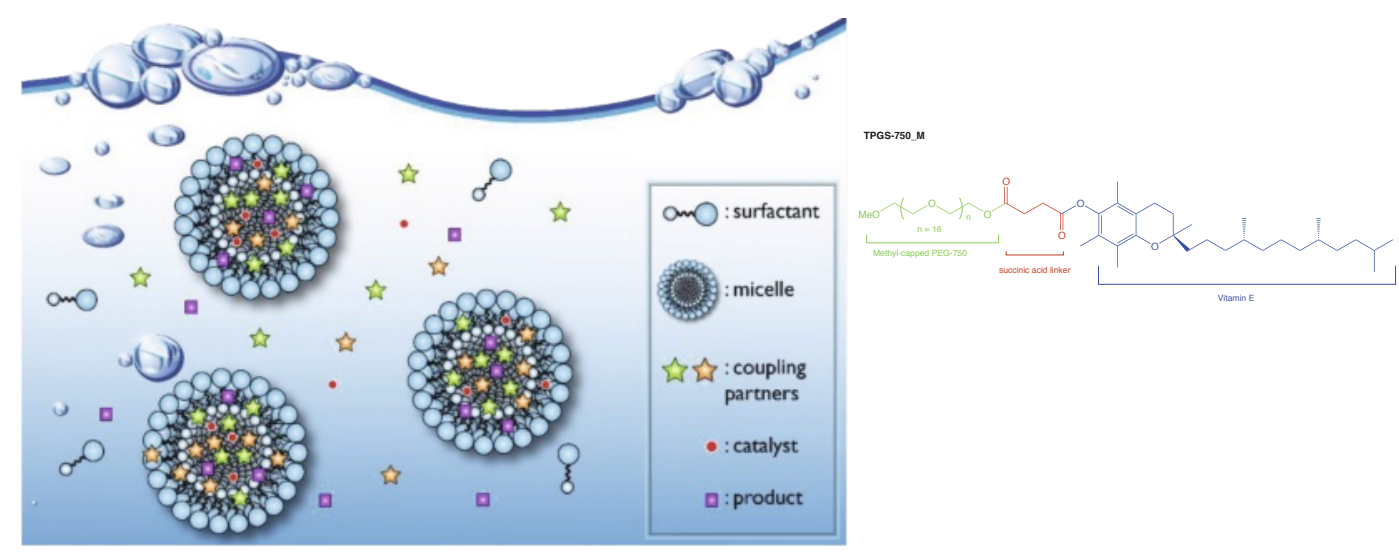

In the process of our preliminary evaluation, we were very early fortunate to discover the enabling technique of organic cosolvent that greatly minimized the impact of physical effects on the reactions. ${ }^{[7 \mathrm{~d}, 9]}$ Such emulsion transformations were indeed very finicky and prone to scale and mixing dependency. With the mere addition of an additional organic co-solvent in a few percent, typically 5 to $20 \%$, one could significantly reduce the challenges associated with mixing, and other physical changes of the various components of the system (Fig. 2). We knew at this point that the goal was not to remove organic solvents entirely, but rather to phase out undesirable ones and to minimize the usage of better suited ones. We showed numerous times for example that ethyl acetate, or acetone in less than $20 \%$ volume in bulk water could be used instead of the hazardous polar aprotic solvents. ${ }^{[10]}$

Despite concrete and solid experimental data, it took several publications to start convincing the skeptical readership of the impact of the technology. The first landmark came from the assembly of the API in Scheme 1 where we demonstrated the full assembly of the target in bulk water on kg-scale, utilizing an SNAr, Suzuki-Miyaura cross-coupling, amidation and deprotection. ${ }^{[11]}$ Comparative analysis from an environmental, cost, and productivity perspective showed about thirty percent environmental footprint reduction, about seventy percent productivity increase and thirty percent cost improvement. Furthermore, we could demonstrate on an analogous compound that the mild conditions of the micellar approach could prevent the need for a THP protective group on the pyrazole, when using MIDA boronate. ${ }^{[12]}$

Fig. 2. Illustration of the co-solvent effect.
Encouraged by these results obtained very early on in our efforts (2012-13), ${ }^{[96,13]}$ we aimed at expanding the toolbox to tackle as many chemical transformations as possible utilizing this streamlined strategy. We engaged in what became phenomenally productive collaborations with two brilliant partners, Professors Bruce Lipshutz (UCSB) and Sachin Handa (University of Louisville). Within our partnership, several synthetic methodologies were reported encompassing the use of the technology on critical transformations such as $\mathrm{SNAr},{ }^{[14]}$ amide bond formation, ${ }^{[7 a, 9 b, 15]}$ Click chemistry, ${ }^{[16]}$ nitro aromatic ${ }^{[17]}$ and alkyl reductions, ${ }^{[18]}$ nitro alkyl alpha-functionalization, ${ }^{[19]}$ photo-redox catalysis, ${ }^{[20]}$ asymmetric gold catalysis, ${ }^{[21]}$ Sonogashira[ ${ }^{[22]}$ or Suzuki-Miyaura ${ }^{[23]}$ or Buchwald-Hartwig ${ }^{[24]}$ or Negishi ${ }^{[25]}$ crosscouplings, biocatalysis, ${ }^{[26]}$ and various other specific types of chemistry (Fig. 3). ${ }^{[27]}$ During the development of these synthetic methodologies, we not only intended to provide experimental options to address a synthetic need, but also to understand our micellar systems better. Fundamental understanding of the dynamic process associated with micelle formation, along with the compartmentalization effect were from the start seen as essential to ultimately solve the bigger problems. We therefore tackled each of these projects as an opportunity to push the boundaries and to learn more about the physical phenomena associated with micellar chemistry, as we will illustrate in the following section.

\section{Case Study on Suzuki-Miyaura Cross-couplings}

Our first experience on multi-kilogram scale relied on very preliminary reports around Suzuki-Miyaura cross-couplings. ${ }^{[7 b]}$
Designer surfactant in water (diameter $\times \mathbf{n m}$ )

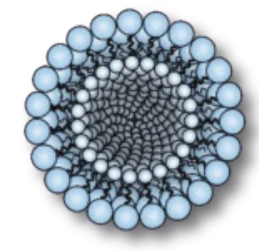

I-20\% organic co-solvent

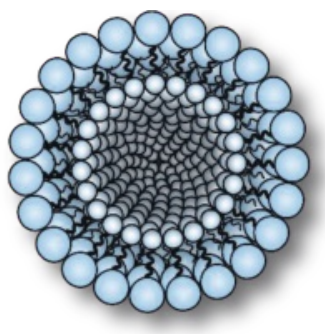

Designer surfactant in water/co-solvent (diameter $2 \times \mathrm{nm}$ ) additional benefits: increased rate of reactions, ease of reaction handling such as additions, transfers, end product isolation...

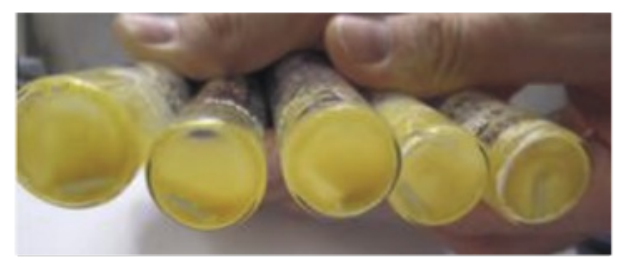

Some failed addition of solvents

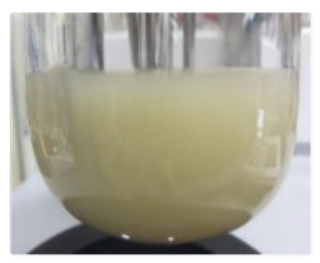

Reaction mixture containing a surfactant with or without a solvent 


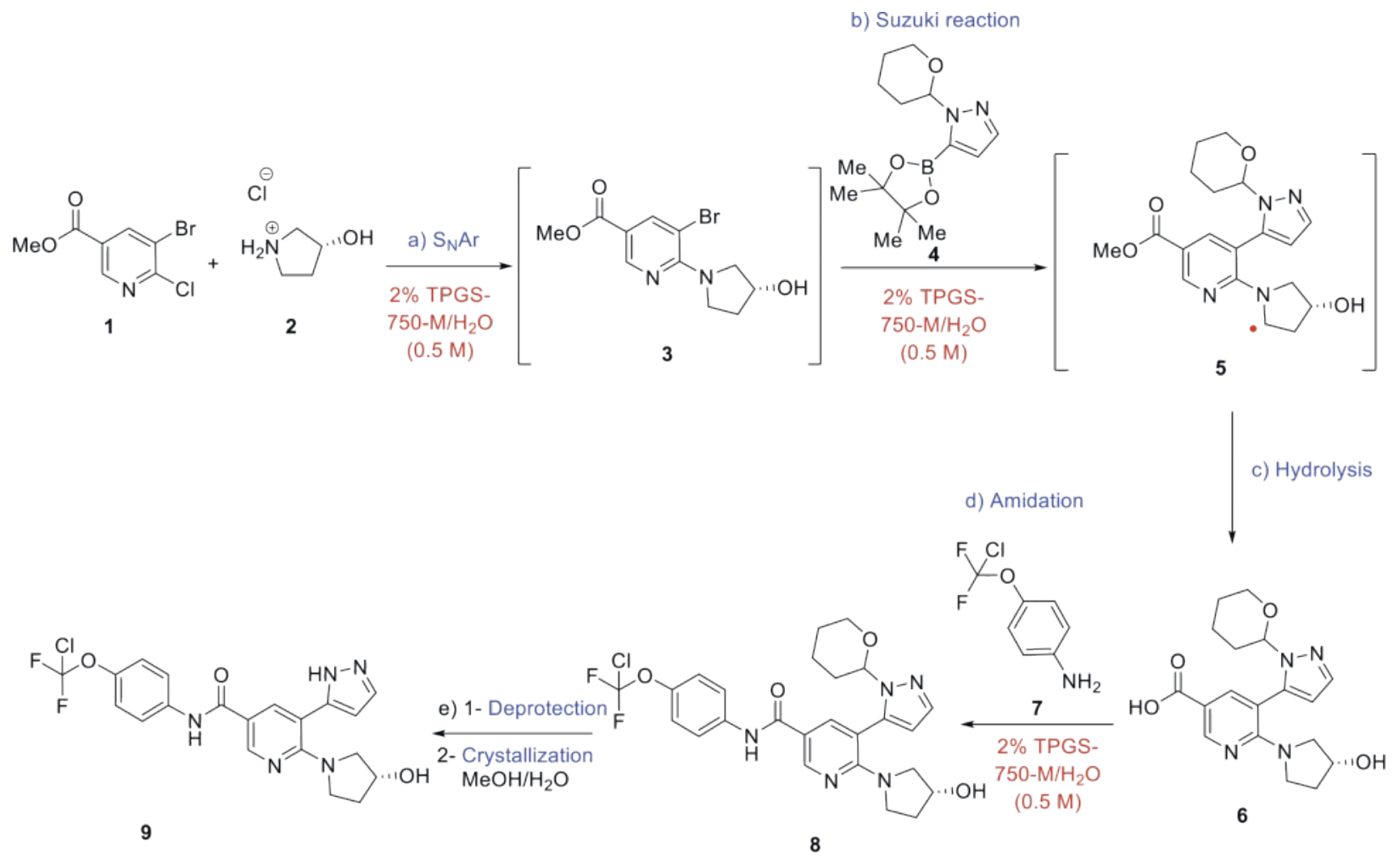

a) base, rt, $12 \mathrm{~h}$; b) base, $\mathrm{Pd}$ catalyst, $40^{\circ} \mathrm{C}, 6 \mathrm{~h}$; c) $\mathrm{NaOH}, \mathrm{MeOH} / \mathrm{H}_{2} \mathrm{O}, \mathrm{rt}, 6 \mathrm{~h}$ then $\mathrm{HCl}$; d) coupling agent, base, rt, $10 \mathrm{~h}$; e) $1-\mathrm{HCl}, \mathrm{MeOH}, \mathrm{rt}, 6 \mathrm{~h}, 2$ - then crystallization

Scheme 1. The first scaled-up assembly of an API with the surfactant technology.

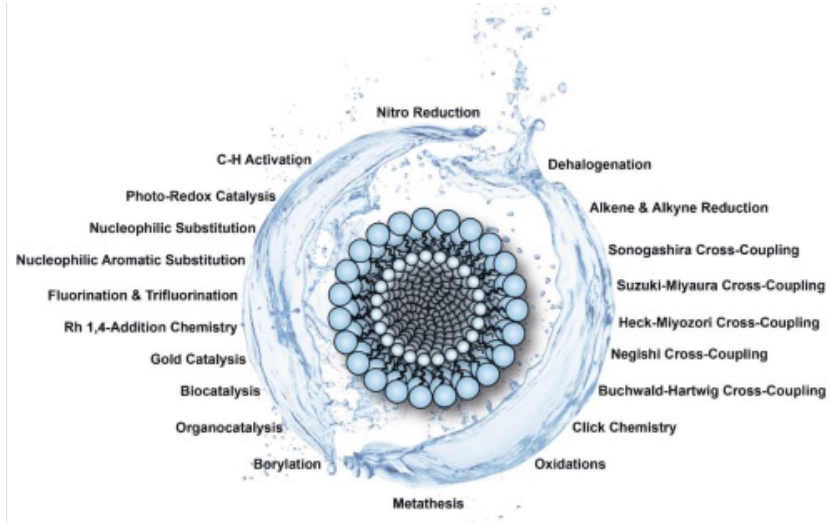

Fig. 3. Current chemistry toolbox with the surfactant technology.

We were attracted by a micellar approach as we encountered stability issues around the use of both the boronate ester and the 2-bromo-pyridine. The technology indeed seemed like an obvious choice as it could enable such cross-couplings under mild conditions. We had observed rapid protodebromination especially upon even gentle heating, which implied the use of a large excess of this expensive moiety. Besides, the boronate ester would also be rather unstable, being prone to the well-known protodeboronation of 2-substituted heteroaryl species. An additional issue was the high basicity of the two coupling partners and of the product itself. This resulted in making all these chemicals good ligands for the metal catalyst, thus requiring high loading, and hence into painstaking and overall low yielding work-up to ensure their removal in the final drug substance. Switching to the surfactant technology, we identified TPGS-750-M as being the optimal surfactant, along with acetone and triethylamine as the optimal co-solvent and base.
Continued optimization and screening revealed the lipophilic ligand dtbpf to be even superior to the originally reported dppf ligand (see Fig. 4). Under these conditions, we could enable the cross-coupling at room temperature in almost quantitative yield. Slight amounts of protodeboronation (only $3 \%$ of the boronate ester would protodeboronate under such conditions after $6 \mathrm{~h}$, and much less was observed thanks to a slow controlled addition) and protodebromination were the main impurities observed. Very interestingly, we could also greatly facilitate the process as lower amount of catalyst was used that required simple washing with cysteine prior to the crystallization to result to well below 100 ppm in the isolated crystalline product (Fig. 5).

The process described above turned out to function very reliably and predictably on multi-tens of kilogram scale, and to be fairly general and amenable to a wide range of difficult heterocycles. ${ }^{[23 \mathrm{~h}]}$ This first large scale process conducted on multi-tens of kilograms was also an eye-opener as to the necessity to understand and match the partitioning of the various reaction components. Both coupling partners and the catalytic system indeed have to be in the same compartment of the system. We were, and are still to a large extent, however unable to reliably predict and design the proper compartmentalization effect of the various reaction components. Besides, while we originally thought the chemistry should occur within the core micelles to benefit from the full advantages associated with the nano-reactors that they constitute, this was definitely not the only option as the chemistry could also occur at the PEGylated interface. Only water would turn out to be an unfavorable compartment for reactivity. Nevertheless, this project had showed the necessity to not only screen for ligands, or source of transition-metal catalyst, but also to best design the nature of the coupling partners for the medium itself.

Based on these findings, we therefore included computational evaluation whenever possible to shed insight into the chemical 
Fig. 4. Evolution of the reaction conditions for a challenging Suzuki-Miyaura cross-coupling.<smiles>[R]C(=O)c1nc(B2OC(C)(C)C(C)(C)O2)cnc1[R]</smiles><smiles>[R3]c1cccnc1Br</smiles><smiles>[R]C(=O)c1nc(-c2ncccc2[R3])cnc1[R]</smiles>

\section{Original conditions:}

Boronate ester (1.0 eq), 2-bromopyridine (1.05 eq), $\mathrm{PdCl}_{2}$ (dppf)DCM (5 mol\%), $\mathrm{K}_{3} \mathrm{PO}_{4}(2.5 \mathrm{eq}), \operatorname{THF}(17 \mathrm{v}), \mathrm{H}_{2} \mathrm{O}(3 \mathrm{v}), 50^{\circ} \mathrm{C}, 5 \mathrm{~h}, 60 \%$ yield

\section{Revised conditions:}

Boronate ester (1 eq), 2-bromopyridine (1.20 eq), $\mathrm{PdCl}_{2}$ (dtbpf) (2 mol\%), $\mathrm{Et}_{3} \mathrm{~N}$ (2 eq), acetone (2 v), 2\% TPGS-750-M/ $\mathrm{H}_{2} \mathrm{O}$ (15 v), rt, overnight, $>95 \%$ isolated yield

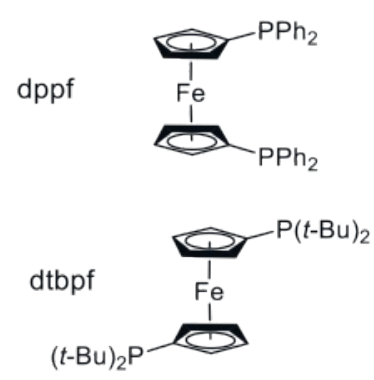

Fig. 5. Brief overview of the chemical process.

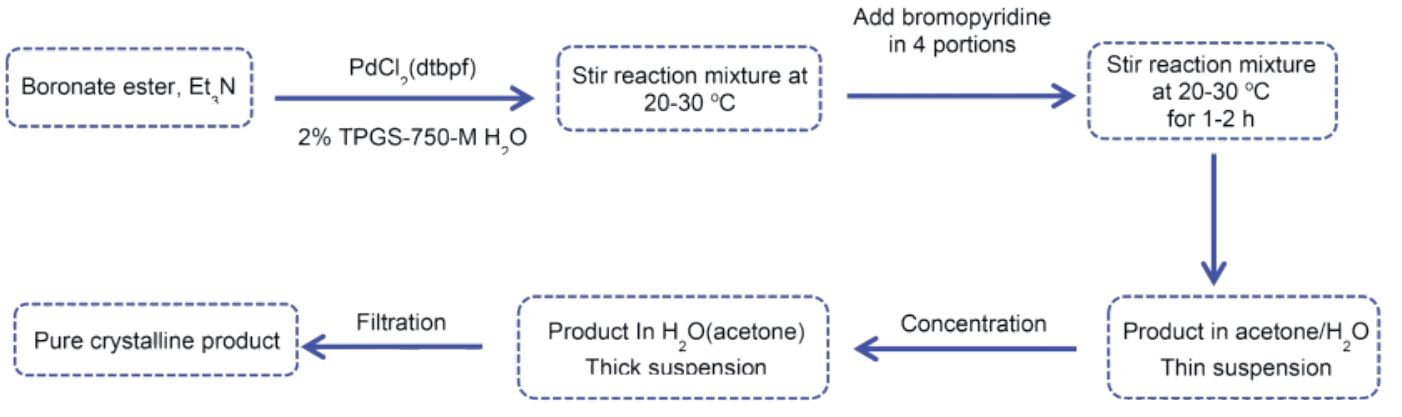

transformation. Synthetically, we also tried to 'regain control' and dictate the compartment where the chemistry was to occur. In order to do so, we designed two approaches for the PEGylated region and the core of the micelles.

For the PEGylated region, we envisioned a 'nano-to-nano' effect, whereby nano-particles containing the suitable catalytic species would be entrapped into the PEG side-chains. Such a heterogeneous catalysis approach has been exemplified in the past, but never in the context of micellar chemistry. ${ }^{[23 k]}$ After tremendous work to identify the optimal nano-particles for the system, we identified reduced iron chloride as being a suitable support of e.g. palladium and S-Phos to catalyze Suzuki-Miyaura crosscoupling. Very interestingly, a remarkable activity of the nanoparticles was observed, much improved compared to all other precious metals with full conversion under mild conditions with as little as ca. 300 ppm palladium for Suzuki-Miyaura crosscoupling. The nano-particles are easily prepared by reduction of iron trichloride by Grignard reagent in THF and doped in situ with either $c a .80 \mathrm{ppm}$ of palladium acetate, if required for nitro reduction, or $c a .300 \mathrm{ppm}$ of the same palladium acetate and a suitable ligand in equimolar amount, SPhos or XPhos respectively for Suzuki-Miyaura or Sonogashira cross-couplings (Fig. 6). The nano-particles can be isolated after removal of the solvent and gentle drying, stored under inert atmosphere or used as such in the transformation. Excellent yields of coupling products, and broad substrate scope were demonstrated, along with easy recycling of the catalyst and of the reaction medium due to the heterogeneous nature of the chemistry.

The impact of the technology can be demonstrated on the following consecutive cross-coupling that results very simply in $87 \%$
Fig. 6. Preparation of palladiumdoped iron nano-particles.
80 or $320 \mathrm{ppm} \mathrm{Pd}(\mathrm{OAc})_{2}$ (+ Ligand)

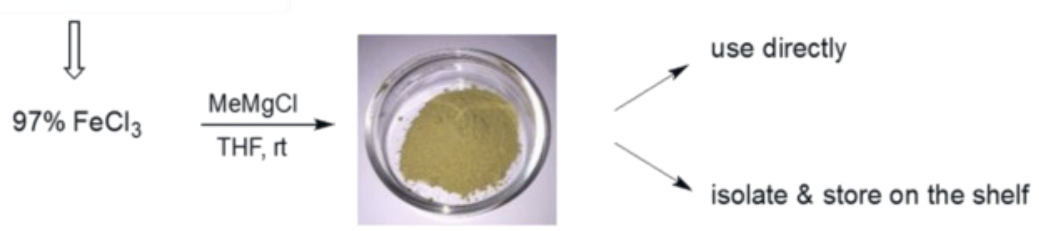

Fe/ppm Pd nanoparticles
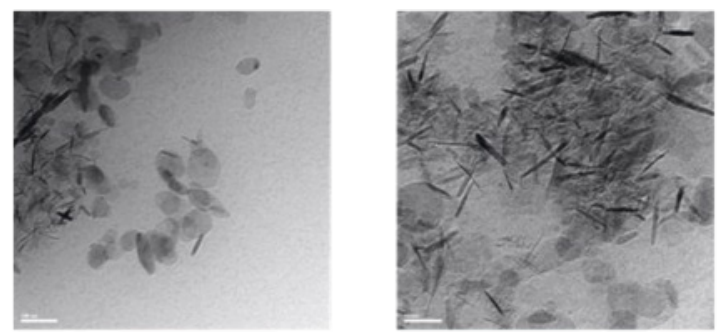

Cryo-TEM analyses of Fe/ppm Pd NPs 
isolated of the desired product after consecutive selective crosscoupling onto the symmetrical dichloropyridine (Scheme 2). Only a pinch of $300 \mathrm{ppm}$ of palladium-doped iron nano-particle is required for the first transformation, which is complemented with a second pinch for the second coupling (unpublished results).

The concept was exemplified on other types of transformations, Sonogashira cross-couplings, ${ }^{[22 c]}$ nitro reduction ${ }^{[17 a, b, d]}$ and proved extremely powerful when reaction partners have high affinity for the PEGylated region. However, despite most of the technical challenges solved, we are still today struggling to implement the technology on scale for lack of a proper supply chain for the iron nano-particles and their sufficient characterization.

We knew upfront that such an approach using an heterogeneous catalyst would not be the easiest one and had in the meantime started evaluating the complementary option where the catalytic system would sit within the core of the micelles. ${ }^{[28]}$ This was made possible via fine-tuning of the phosphine scaffold of choice and the introduction of three isopropyl groups appended onto a benzyl substituent. The so-called Handaphos ligand with dramatically enhanced lipophilicity compared to BIDime for example was demonstrated computationally to stay much longer within the micelle core, and thus providing much better catalytic activity.
This was again demonstrated on a variety of scaffolds and resulted routinely in complete conversion under mild conditions with 500 to $1000 \mathrm{ppm}$ of palladium (Scheme 3).

While we had here a readily implementable option, the complex nature of the HandaPhos ligand itself made it impractical for large scale use due to the intrinsic complexity of the ligand.

We therefore went back to the drawing board and designed a de novo class of ligand that would achieve the similar goals. We came up with a much simpler biphenyl phosphine series readily available and tunable in 2 steps from commercially available compounds (Scheme 4). With the lead ligand EvanPhos, we demonstrated that such cross-coupling as the one encountered in the API Anacetrapib for example could proceed smoothly and reliably in $91 \%$ yield with as little as 0.05 mol\% of palladium. ${ }^{29]}$

Multiple other APIs were prepared using this strategy with typical loadings of 0.1 to $0.3 \mathrm{~mol} \%$ for standard targets with relative basicity (Scheme 5).

Pushing the concept further, we realized the opportunity created by the well-recognized palladacycle pre-catalyst proposed by Colacot et al. ${ }^{[30]}$ Indeed, we envisioned that such a palladacycle pre-catalyst approach could be utilized to channel the pre-catalyst in the proper region of the reaction mixture, namely the core of the

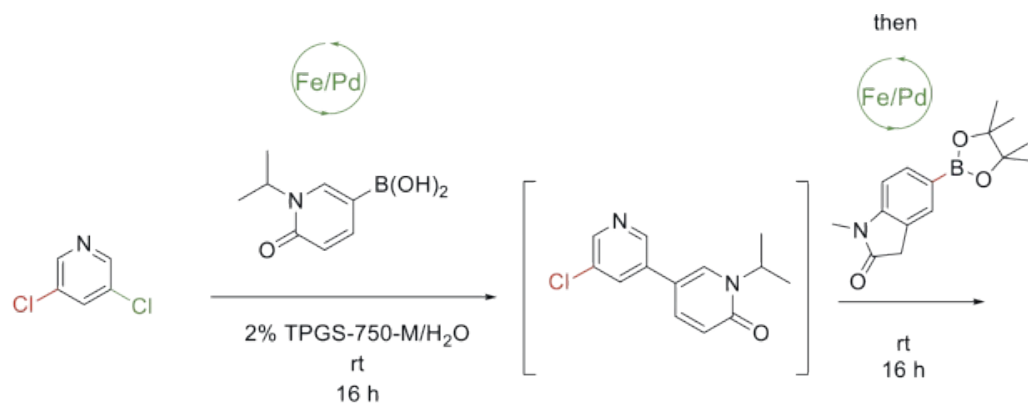

Scheme 2. One application of the nano-particle technology.
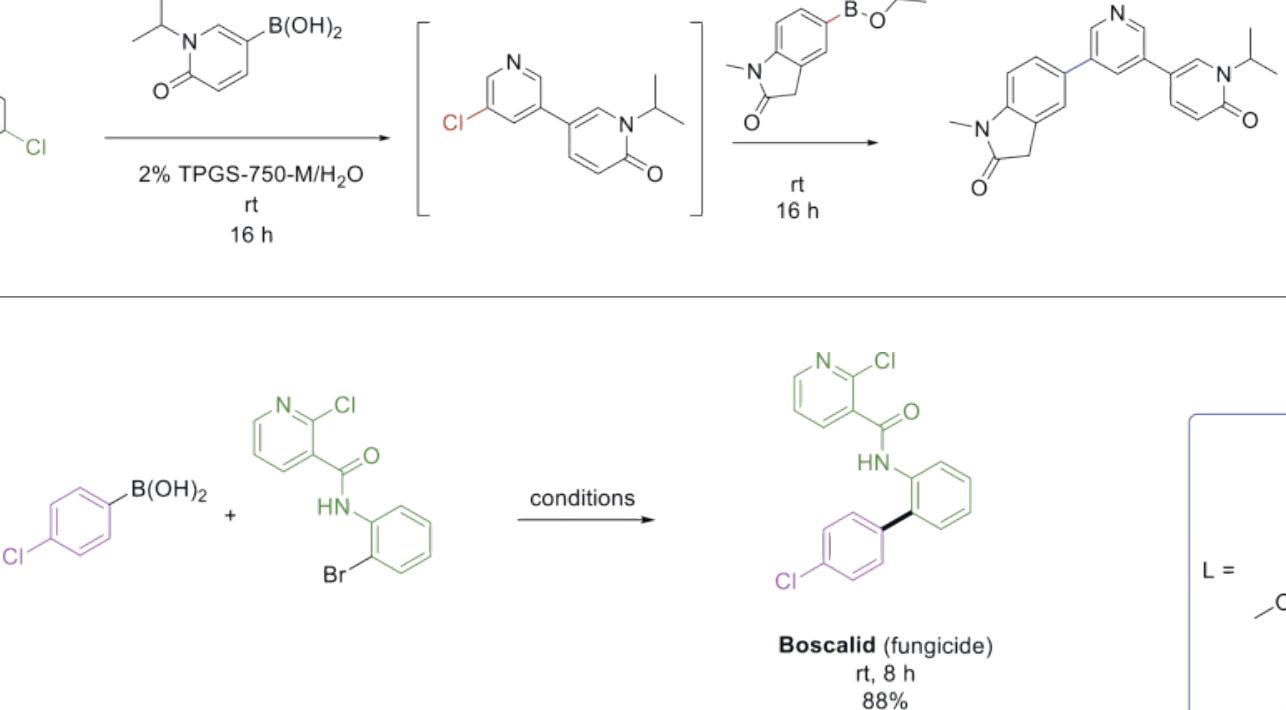

$88 \%$
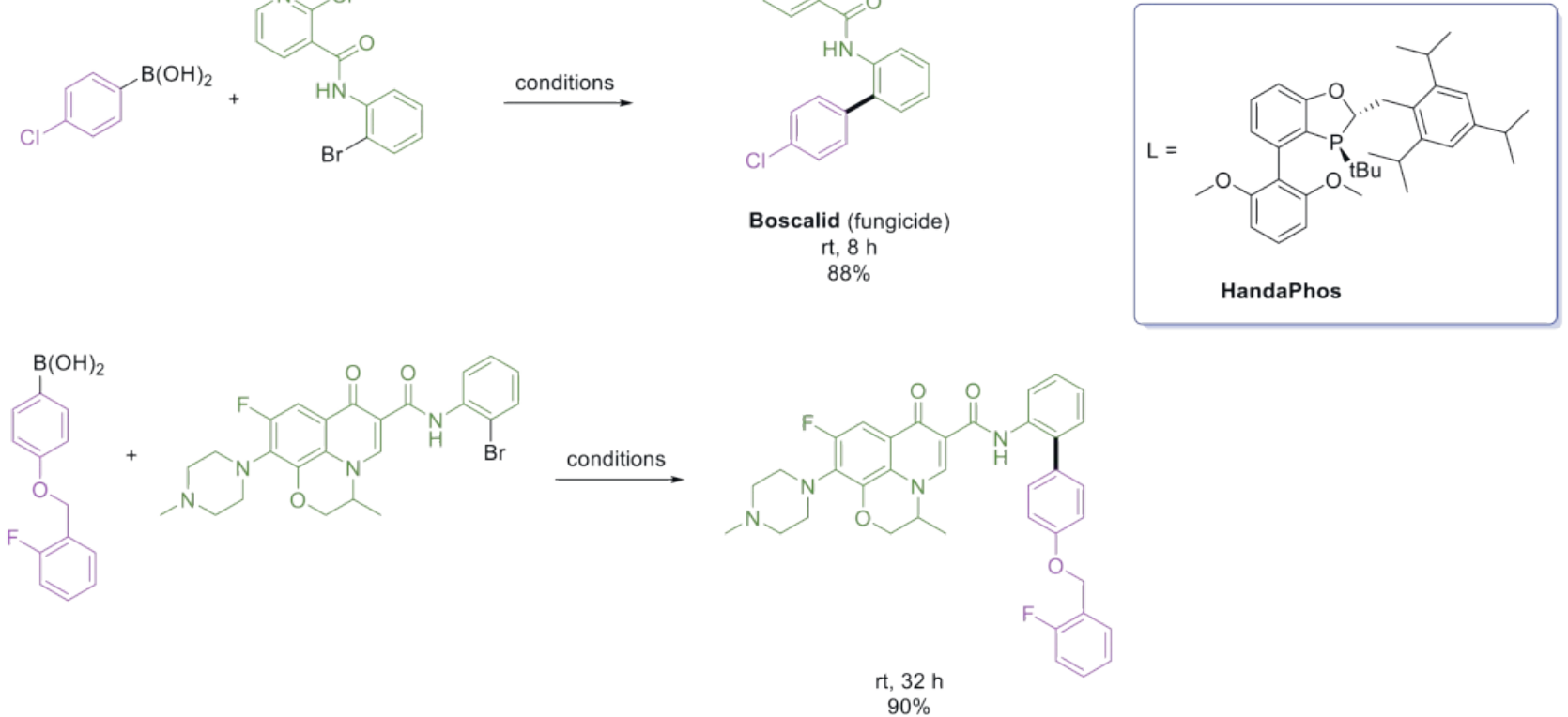

conditions: (L)Pd(OAc) 2 (0.05 mol\%), $\mathrm{NEt}_{3}$ (2 eq), $2 \% \mathrm{Nok} / \mathrm{H}_{2} \mathrm{O}$, rt

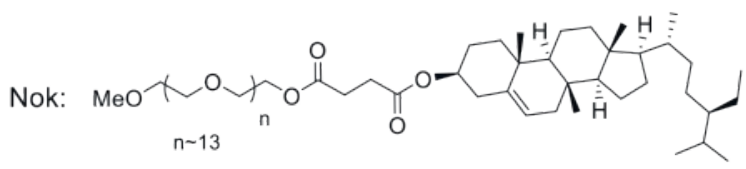


Scheme 4. Design of the

EvanPhos ligand and one example of its application.

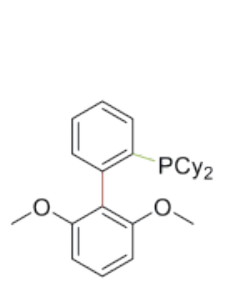

SPhos

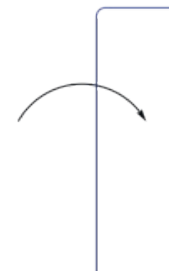

(c)

EvanPhos

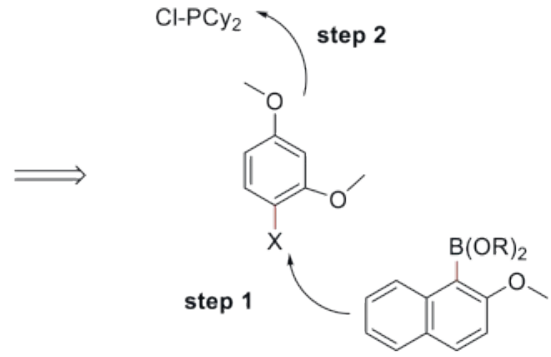

conditions

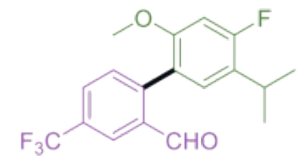

$91 \%$
$1.5 \mathrm{eq}$

conditions: (EvanPhos) $)_{2} \mathrm{Pd}(0.05 \mathrm{~mol} \%)$, pre-reduction of $\mathrm{Pd}(\mathrm{II})$ with $\mathrm{DIBAL}$ in Toluene, $\mathrm{K}_{3} \mathrm{PO}_{4} \cdot \mathrm{H}_{2} \mathrm{O}$ (1.5 eq), TPGS-750-M/ $\mathrm{H}_{2} \mathrm{O}, 45^{\circ} \mathrm{C}, 16 \mathrm{~h}$

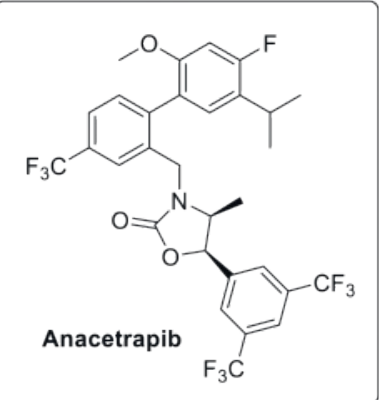

Extension to Buchwald-Hartwig aminations

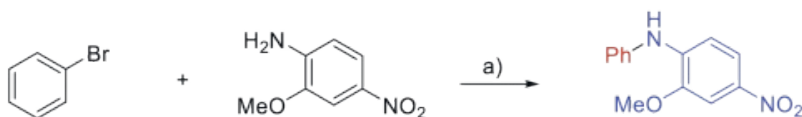

$89 \%$

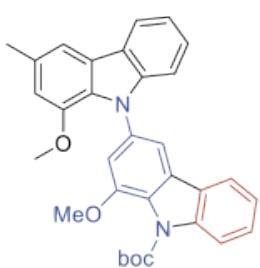

Murrastifoline B

J. Org. Chem. 2015, 80, 5666. Synlett 2014, 25, 1381.

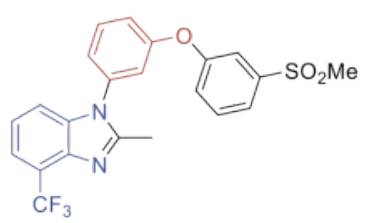

liver $\mathrm{X}$ receptor agonist

Bioorg. Med. Chem. Lett. 2010, 20, 526.

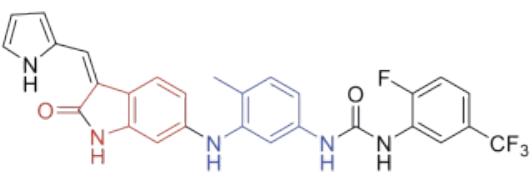

$80 \%$ 

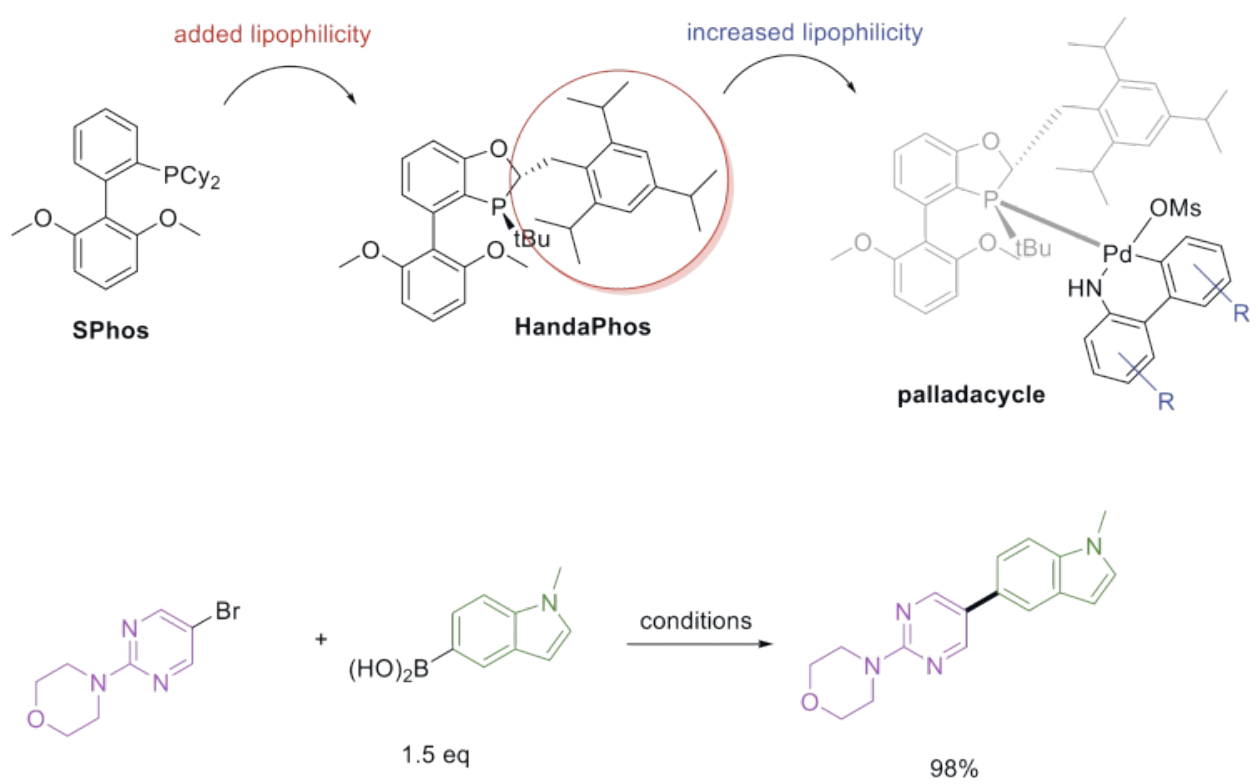

conditions: palladacyle $\mathbf{P}^{\star}, 2 \%$ wt TPGS-750-M/ $\mathrm{H}_{2} \mathrm{O}, \mathrm{NEt}_{3}, 45^{\circ} \mathrm{C}, 16 \mathrm{~h}$ micelles, when the lipophilicity could be properly upgraded. This is actually an easily tunable property of the pre-catalyst in virtue of the derivatization of the amino biphenyl moiety. Exhaustive screening revealed that the bis-isopropyl mesylate derivative was most effective. ${ }^{[31]}$ Combined with the HandaPhos, it could for example promote the Suzuki-Miyaura cross-coupling as shown in Scheme 6 in almost quantitative yields using as little as 0.03 mol\% of active catalyst. We are currently looking and applying the concept with the more readily accessible EvanPhos ligand.

Concomitantly, we investigated the use of the Vitamin E-derived surfactants in biocatalysis to follow up on early leads identified within our laboratories. ${ }^{[13 b]}$ We rapidly confirmed a dramatic reservoir effect that would push further the substrate inhibition and thus enable the biocatalysis at lower solubility enhancers. There was to the best of our knowledge no report of such an effect at the time of our finding. Only shortly afterwards Wallace and Balskus reported similar observations in beautiful experimental work that was utilized to greatly improve the titer of a biocatalytic step. ${ }^{[32]}$ Such a reservoir effect was not unexpected but its amplitude came as a very nice surprise. Indeed, when tuning the lipophilicity properly, we saw substantial improvement with as much as 5-fold improvement when using a greasy ester in place of a standard methyl ester (Fig. 7).

More interestingly, we had demonstrated the compatibility of successive bio/chemo-catalysis which enabled the construction of more and more complex synthetic sequences.

For example, we could easily conduct a 1,4-addition of boronate species onto a Michael acceptor, in an asymmetric fashion or not, and continue with a keto-reductase (Scheme 7). ${ }^{[33]}$ We are extremely excited at these developments that we see as real enablers for our long-term sustainability strategy, and will share more on our progress in the very near future.
Scheme 6. The pre-catalyst concept pushed to its limit with the lipophilic HandaPhos.
While we have learned a lot through these various projects and their developments, we are to a large extent still unable to understand entirely where the chemistry really occurs, and hence to control this via proper design of the various reaction components. We can at best offer a decent rationale as to how and where some of the reaction component(s) sit(s) and partition(s), but still fail in really ensuring truly micellar catalysis. Only then would we get the full benefits of the technology! In order to get there, and to further enrich the scope of the technology, we therefore wanted to revisit the choice of the surfactant itself, as a means to more genuinely 'template' the chemistry. Looking back at the problem at stake, we envisioned proline to be a suitable isostere of the tertiary amide functionality present in the main solvents we were trying to replace. Our brilliant collaborator Professor Sachin Handa complemented the analysis by making a series of analogs and revealed PS-750-M to be such a surfactant of choice (Fig. 8). ${ }^{[34]}$ The candidate correctly exhibited the properties of a surfactant that would rearrange supramolecularly above its CMC into micelles. These micelles were demonstrated to be spherical of $c a .110 \mathrm{~nm}$ diameter size, with the proline core being the most polar part of the molecule. This latter point was of particular interest to us as we wanted, by design, to utilize an anchor within the surfactant to template the other reaction components. I was personally thrilled with the idea as I recognized template elements that I came across a few years earlier in my career when working on the HCV protease inhibitor BILN2061, ${ }^{[35]}$ where the proline sub-unit had been demonstrated to be a strongly chelating moiety within the compound, able to very tightly bond metals when the macrocycle had not yet been formed (Fig. 9, unpublished results). We could not at the time demonstrate whether or not micelles were formed but I felt that we were on the right track. 
Fig. 7. The impact of TPGS-750-M on the kinetic of a biocatalytic ketone reduction.

\section{2-ethylhexyl (E)-3-(4-acetylphenyl)acrylate reduction conversion}
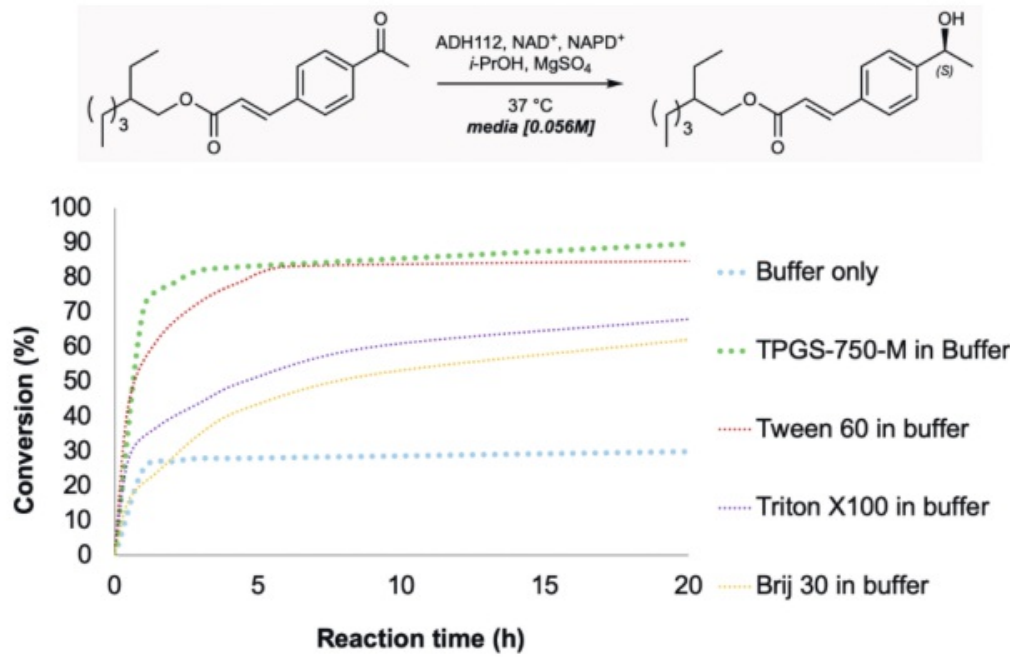

Scheme 7. Recent application of tandem bio-/chemo-catalysis with the surfactant technology.

conditions: a) (BINAP)Rh(nbd)BF 4 (3 mol\%), NEt $3,2 \%$ wt TPGS-750-M/ $/ \mathrm{H}_{2} \mathrm{O}, \mathrm{NEt}_{3}, \mathrm{rt}$; b) $\mathrm{ADH}, \mathrm{NAD}+, \mathrm{NADP}+$, iPrOH, $2 \%$ wt TPGS- $750-\mathrm{M} / \mathrm{H}_{2} \mathrm{O}, \mathrm{MgSO}_{4}, 37^{\circ} \mathrm{C}$, ph 7

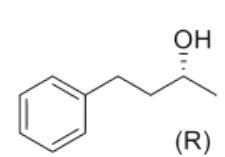

$82 \%$

$>99.8 \%$ e.e $\mathrm{ADH} 101$

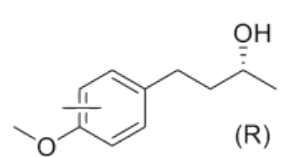

$88 \%$

$>99.9 \%$ e.e. $\mathrm{ADH} 101$

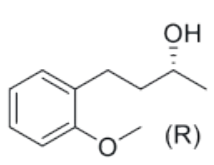

$80 \%$

$>99.9 \%$ e.e. $\mathrm{ADH} 101$

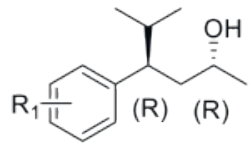

$87 \%$

$>99.9 \%$ e.e.

$>99.4 \%$ d.e.

(R)-BINAP / ADH110
With the surfactant in our hands, we tried to demonstrate that the proline core would indeed serve as a strongly binding subunit within the construct, and to our delight, we could show via cryo-TEM that palladium nano-particles would be exclusively contained within the core of micelles. Further computational stud- ies further confirmed the microscopic measurements and served as good basis for our initial studies (Fig. 10). Cryo-TEM imaging showed for example the presence of palladium nano-particles exclusively in multi-walled micelles, while free energies calculated via COSMO-RS on various PS-750-M adsorption sites had
Fig. 8. Design of the highly polar PS-750-M surfactant.

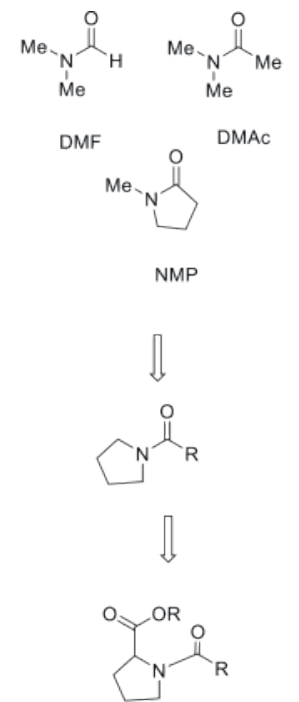

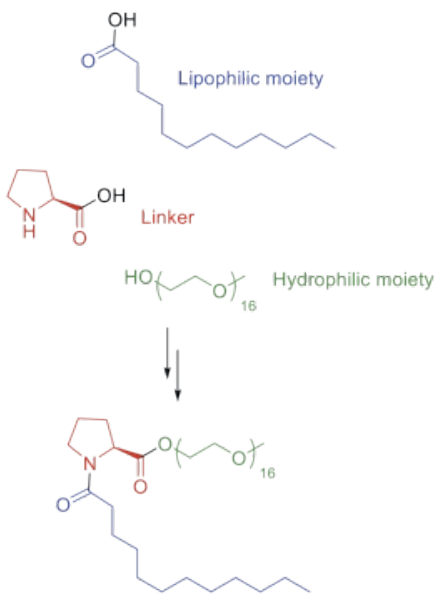

PS-750-M

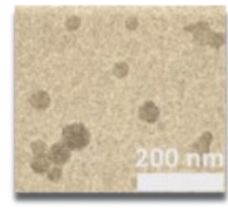

cryo-TEM of PS-750-M

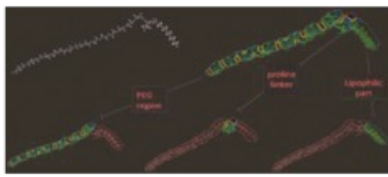




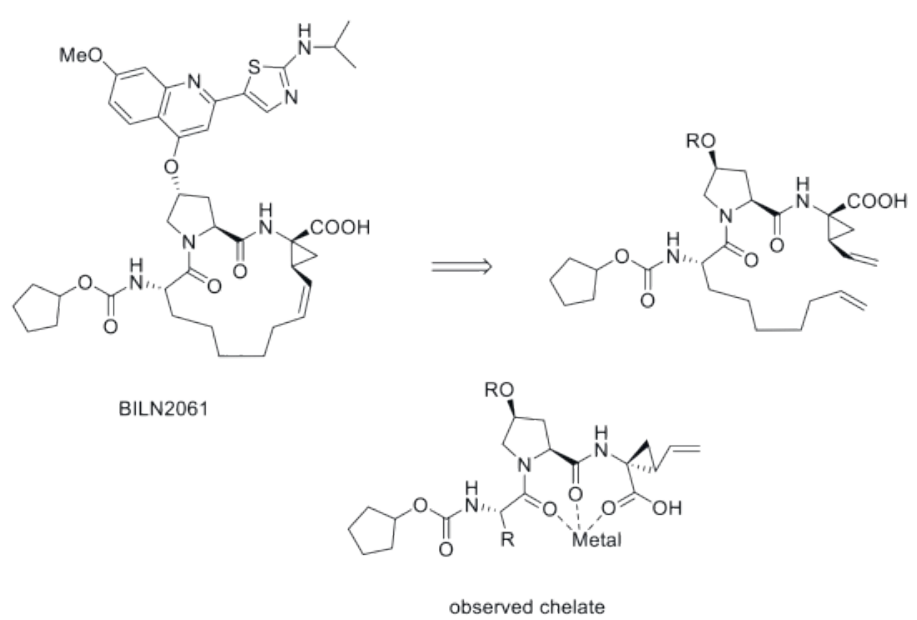

Fig. 9. Early precedents of templating effect around a proline core.

indicated the proline linker to be the site of complexation, ${ }^{[10]}$ as demonstrated by our remarkable collaborators Professor Martin Andersson, from DTU, expert in computational studies, and Dr. Maarten Nachtegaal, from the Paul Scherrer Institute, expert in the characterization of complex objects via state-of-the-art analytical techniques (Fig. 11).

With such a surfactant in our hands, we first investigated the alpha-arylation of nitro alkyl systems. ${ }^{[36]}$ Such transformations are known to require highly polar media, typically NMP or DMF, and failed with the less polar TPGS-750-M. We could here promote such challenging coupling with a substituted pyridine and nitro ethane in $65 \%$ isolated yield utilizing [t-BuXPhos)Pd(allyl)] OTf as the catalytic system (Scheme 8).

The next step consisted in further optimization of the catalytic system, relying here on the propensity of nano-particles to sit in the most polar region of such micellar systems. To our delight, our newly formed mixed copper-palladium nano-particles supported on charcoal ${ }^{[37]}$ were proven to exhibit suitable behavior, sitting within the proline template, and promoting the chemistry in this part of the compartment of the system (Fig. 12). A remarkable synergy between the bimetallic nano-particles and the charcoal support was demonstrated, by XAS analysis, with each metal ensuring the catalysis via linkage with a phosphine ligand as revealed by ${ }^{31} \mathrm{P}$ NMR. ${ }^{[38]}$ These conditions resulted in a broad substrate scope in a series of highly selective and sustainable cross-couplings transformations, such as Buchwald-Hartwig, Sonogashira or Suzuki-Miyaura (Scheme 9). [39]

\section{Conclusion}

Our journey has led us from the mere substitution of an undesirable solvent by a more appropriate medium, to an entirely different world with water as the bulk medium, and governed by novel rules. We started tailoring the systems, whether the synthetic sequences, or the nature of the experimental conditions, which resulted in tremendous learnings about the profound impact of the compartmentalization effect especially. These results have further raised expectations, as we now target even more active heterogeneous catalytic systems to take further advantage of our increased understanding of the compartmentalization, and start entering new technological fields. ${ }^{[40]}$ We strongly believe that leveraging genuine micellar phenomena will enable highly selective and effective chemistry, with a wide scope of transformations enabled, as Nature does!

\section{Acknowledgements}

The many scientists who have made our journey into the field of surfactant chemistry successful, more particularly Dr. Michael Parmentier, Dr. Pengfei Guo, Dr. Jianguang Zhou, Dr. Bin Wu, Dr. Ning Ye, the brilliant students from UCSB who helped us transfer the technology Dr. Nick Isley, Dr. Christopher Gabriel, Dr. Daniel Lippincott, Dr. Margery Cortes, who also is the author of the design in this manuscript, impactful managers who have supported the start and continuation of our initiative Dr Heiko Potgeter, Dr. Xiangdong Feng, Dr. Thomas Heinz, Dr. Andreas Knell, Dr. Daniel Kaufmann, Dr. Martin Spormann, Dr. Reto Fischer, Dr. Larry Hamman, and our incredible collaborators mentioned earlier Professor Bruce Lipshutz from the University of California at Santa Barbara, Professor Sachin Handa, from the University of Louisville, Professor Martin Andersson, now at the Danish Technical University, Dr. Maarten Nachtegaal from the Paul Scherrer Institute, and precious newcomers and supporters Professor Christof Sparr from the University of Basel, Professors Dieter Seebach and Peter Walde from the ETH Zurich for their continued support.

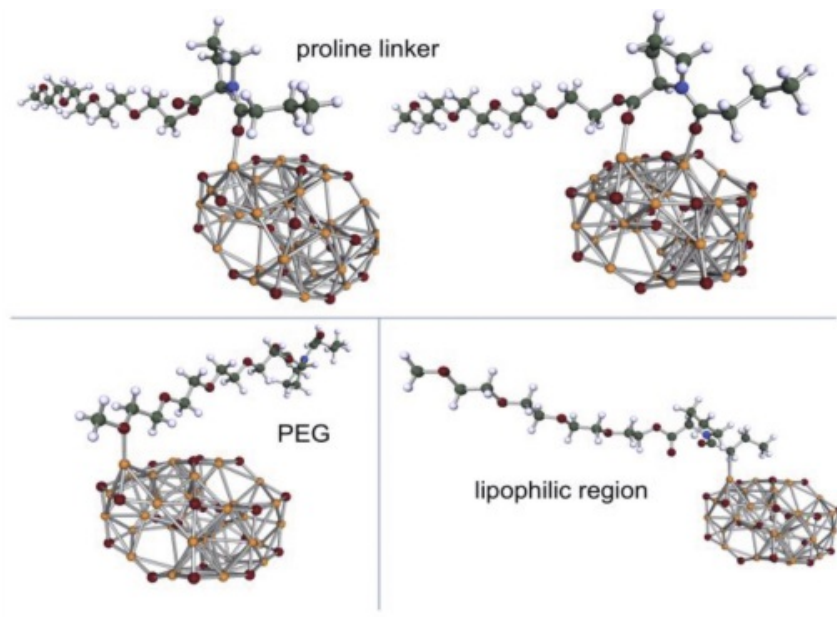

Fig. 10. Molecular structures of the various adsorption geometries of the short model PS-750-M surfactant to the $\mathrm{Cu}(\mathrm{I})$ nanoparticle and calculated free energies.

\begin{tabular}{|cc}
\hline PS-750-M adsorption site & $\begin{array}{c}\text { COSMO-RS free energies }(\mathrm{kJ} / \mathrm{mol}) \\
\text { for the reaction in PS-750-M }\end{array}$ \\
\hline PEG region & 42 \\
proline linker & -3 \\
lipophilic region & 109 \\
\hline
\end{tabular}




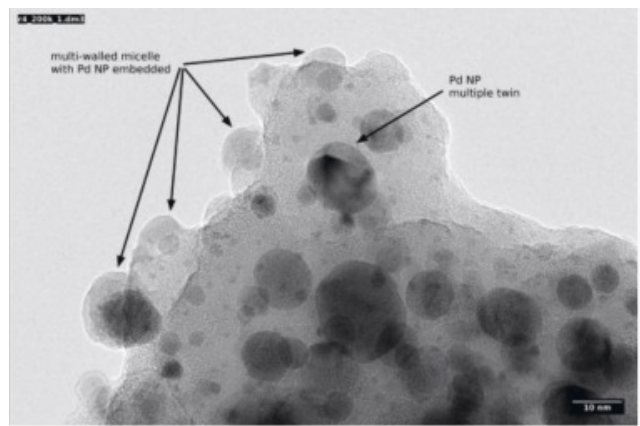

Fig. 11. Cryo-TEM analysis of nanoparticles in PS-750-M water.
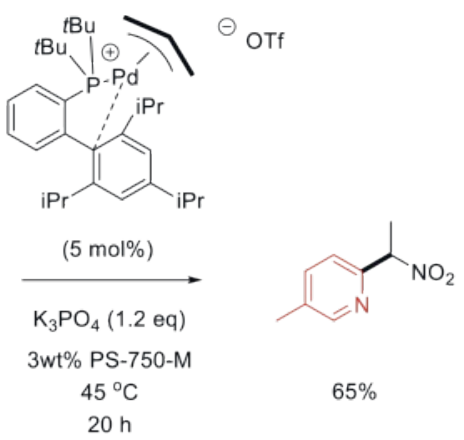

Scheme 8. Early application of the proline-based surfactant.
Fig. 12. Synergistic effect of doubly-doped carbon surface in micellar catalysis.

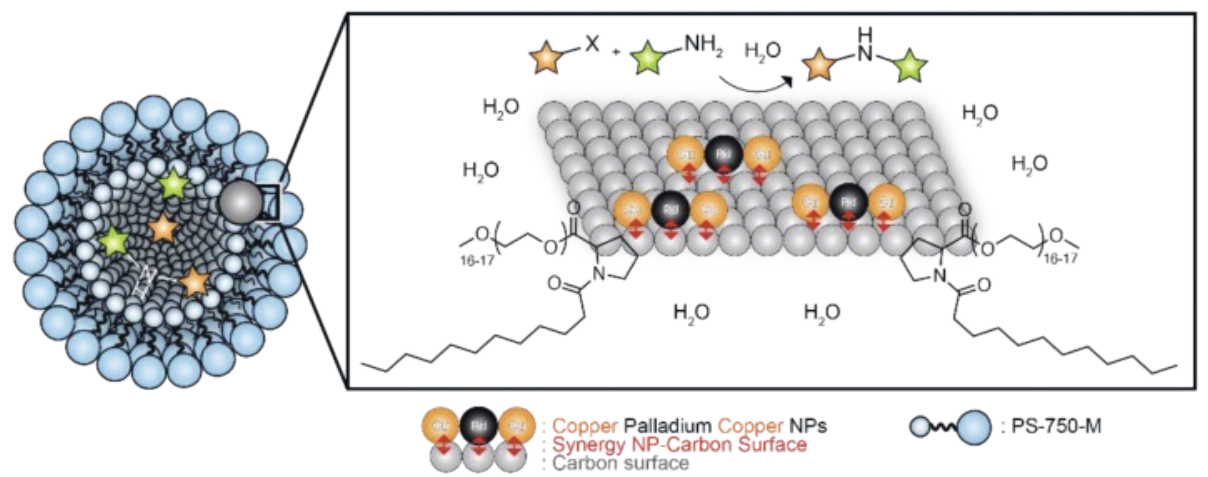

Suzuki-Miyaura cross-coupling<smiles>Clc1ccc(Br)cc1</smiles>

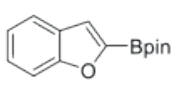

$1.2 \mathrm{eq}$

conditions

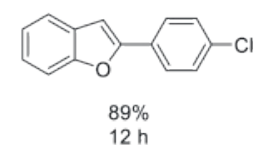

Sonogashira cross-coupling<smiles>Brc1ncccn1</smiles><smiles>C#Cc1ccc(OC)cc1</smiles>
conditions $1.2 \mathrm{eq}$

Buchwald-Hartwig amination<smiles>Clc1ccc(Br)cc1</smiles><smiles>COc1ccc2[nH]ccc2c1</smiles>

conditions

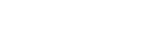

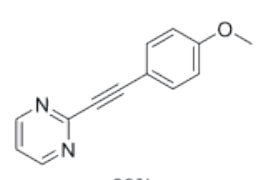

$89 \%$
$13 \mathrm{~h}$

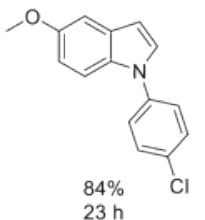

conditions: nanocatalyst ( $1 \mathrm{~mol} \%$ based on Pd), $\mathrm{KOH}(4 \mathrm{eq}), 3 \% \mathrm{PS}$ $750-\mathrm{M}, 60^{\circ} \mathrm{C}$

nanocatalyst prepared in situ - standard conditions: $\mathrm{Pd}(\mathrm{OAc})_{2}(1 \mathrm{~mol} \%)$, $\mathrm{Cu}\left(\mathrm{CH}_{3} \mathrm{CN}\right)_{4} \mathrm{PF}_{6}(2 \mathrm{~mol} \%), \operatorname{cBRIDP}(3 \mathrm{~mol} \%)$, carbon (1 eq)

Scheme 9. Extension of the use of PS-750-M and supported polymetallic catalysis.

[1] a) L. Bergkamp, N. Herbatschek, Rev. Euro. Comp. Int. Env. Law 2014, 23, 221 ; b) See for example https://echa.europa.eu/substance-information/-/ substanceinfo/100.000.617 [Accessed 2 Feb. 2020].

[2] a) B. Barwinski, P. Migowski, F. Gallou, G. Franciò, W. Leitner, J. Flow Chem. 2017, 7, 41; b) C. G. Piscopo, F. Gallou, W. Leitner, G. Francio, Synthesis 2017, 49, 353.

[3] a) J. Lopez, S, Pletscher, A. Aemissegger, C. Bucher, F. Gallou, Org. Proc. Res. Dev. 2018, 22, 494; b) 'Green synthesis of mono- and disubstituted pyridine via aromatic nucleophilic substitution', https://edoc.unibas. ch/30592/1/2013_648.pdf [Accessed 2 Feb. 2020]; c) F. Gallou, M. SeegerWeibel, D. Lupp, Chimia 2011, 65, 877.

[4] a) R. N. Butler, A. G. Coyne, Chem. Rev. 2010, 110, 6302; b) S. Narayan,
J. Muldoon, M. G. Finn, V. V. Fokin, H. C. Kolb, K. B. Sharpless, Angew. Chem. Int. Ed. 2005, 44, 3275; c) S. R. K. Minkler, B. H, Lipshutz, N. Krause, Angew. Chem. 2011, 123, 7966; d) L. Lempke, A. Ernst, F. Kahl, R. Weberskirch, N. Krause, Adv. Synth. Catal. 2016, 358, 1491; e) S. Kobayashi, I. Hachiya, J. Syn. Org. Chem. Jpn. 1995, 53, 370; f) S. Kobayashi, T. Wakabayashi, H. Oyamada, Chem. Lett. 1997, 831; g) S. Kobayashi, S. Nagayama, T. Busujima, Chem. Lett. 1997, 959; h) S. Kobayashi, S. Nagayama, T. Busujima, J. Am. Chem. Soc. 1998, 120, 8287.

[5] a) B. H. Lipshutz, A. R. Abela, Org. Lett. 2008, 10, 5329; b) B. H. Lipshutz, T. B. Petersen, A. Abela, Org. Lett. 2008, 10, 1333; c) R. Moser, S. Huang, A. Abela, B. H. Lipshutz, Chem. Today 2010, 28, 50; d) B. H. Lipshutz, S. Ghorai, Aldrichimica Acta 2008, 41, 59; e) A. Abela, Z. Boskovic, T. Nishikata, C. Duplais, A. Krasovsky, B. H. Lipshutz, Top. Catal. 2010, 53, 985.

[6] B. H. Lipshutz, S. Ghorai, A. R. Abela, R. Moser, T. Nishikata, C. Duplais, A. Krasovskiy, J. Org. Chem. 2011, 76, 4379.

[7] a) C. M. Gabriel, M. Keener, F. Gallou, B. H. Lipshutz, Org. Lett. 2015 , 17, 3968; b) F. Gallou, N. A. Isley, A. Ganic, U. Onken, A. Parmentier, Green Chem. 2016, 18, 14; c) N. A. Isley, R. T. H. Linstadt, S. M. Kelly, F. Gallou, B. H. Lipshutz, Org. Lett. 2015, 17, 4734; d) F. Gallou, P. Guo, M. Parmentier, J. Zhou, Org. Proc. Res. Dev. 2016, 20, 1388; e) M. Parmentier, M. K. Wagner, K. Magra, F. Gallou, Org. Proc. Res. Dev. 2016, 20, 1104; f) B. H. Lipshutz, F. Gallou, S. Handa, ACS Sust. Chem. Eng. 2016, 4, 5838.

[8] B. H. Lipshutz, J. Org. Chem. 2017, 82, 2806.

[9] a) C. M. Gabriel, N. R. Lee, F. Bigorne, P. Klumphu, M. Parmentier, F. Gallou, B. H. Lipshutz, Org. Lett. 2017, 19, 194; b) F. Gallou, M. Parmentier, J. Zhou, P. Guo, WO2017168303.

[10] M. P. Andersson, F. Gallou, P. Klumphu, B. S. Takale, B. H. Lipshutz, Chem. Eur. J. 2018, 24, 6778.

[11] F. Gallou, N. A. Isley, A. Ganic, U. Onken, M. Parmentier, Green Chem. 2016, 18, 14.

[12] M. Parmentier, C. M. Gabriel, P. Guo, N. A. Isley, J. Zhou, F. Gallou, Curr. Op. Green Sust. Chem. 2017, 7, 13.

[13] a) N. Isley, F. Gallou, B. H. Lipshutz, J. Am. Chem. Soc. 2013, 135, 17707; b) J. Zhou, P. Guo, Y. Gai, M. Parmentier, F. Gallou, W. Kong, WO2018134710; c) F. Gallou, M. Parmentier, WO2018060843; d) F. Gallou, P. Guo, J. Zhou, M. Parmentier, WO2018011696.

[14] N. R. Lee, F. Gallou, B. H. Lipshutz, Org. Proc. Res. Dev. 2017, 21, 218.

[15] M. Parmentier, M. K. Wagner, K. Magra, F. Gallou, Org. Proc. Res. Dev. 2016, 20, 1104

[16] A. Adenot, E. B. Landstrom, F. Gallou, B. H. Lipshutz, Green Chem. 2017 $19,2506$.

[17] a) J. Feng, S. Handa, F. Gallou, B. H. Lipshutz, Angew. Chem. Int. Ed. 2016, 55, 8979; b) C. M. Gabriel, M. Parmentier, C. Riegert, M. Lanz, S. Handa, B. H. Lipshutz, F. Gallou, Org. Proc. Res. Dev. 2017, 21, 247; c) N. R. Lee, A. A. Bikovtseva, M. Cortes-Clerget, F. Gallou, B. H. Lipshutz, Org. Lett. 2017, 19, 6518; d) H. Pang, F. Gallou, H. Sohn, J. Camacho-Bunquin, M. Delferro, B. H. Lipshutz, Green Chem. 2018, 20, 130. 
[18] N. A. Isley, M. S. Hageman, B. H. Lipshutz, Green Chem. 2015, 17, 893.

[19] J. Brals, J. D. Smith, F. Ibrahim, F. Gallou, S. Handa, ACS Catal. 2017, 7, 8331.

[20] a) M.-J. Bu, C. Cai, F. Gallou, B. H. Lipshutz, Green Chem. 2018, 20, 1233; b) L. Finck, J. Brals, B. Pavuluri, F. Gallou, S. Handa, J. Org. Chem. 2018 , 83, 7366; c) J. D. Smith, A. Jamhawi, J. B. Jasinski, F. Gallou, J. Ge, R. Advincula, J. Liu, S. Handa, Nature Comm. 2019, 10, 1837.

[21] P. Klumphu, C. Desfeux, S. Handa, Y. Zhang, F. Gallou, B. H. Lipshutz, Chem. Sci. 2017, 8, 6354 .

[22] a) S. Handa, J. D. Smith, Y. Zhang, B. S. Takale, F. Gallou, B. H. Lipshutz, Org. Lett. 2018, 20, 542; b) M. Jakobi, F. Gallou, C. Sparr, M. Parmentier, Helv. Chim. Acta 2019, 102, e1900024; c) S. Handa, B. Jin, P. P. Bora, Y. Wang, X. Zhang, F. Gallou, J. Reilly, B. H. Lipshutz, ACS Catal. 2019, 9, 2423; d) B. Jin, F. Gallou, J. Reilly, B. H. Lipshutz, Chem. Sci. 2019, 10, 3481 .

[23] a) K. Y. Nandiwale, Y. Mo, V. Schultz, A. Pomberger, K. F. Jensen, B. Jin, A. B. Wood, F. Gallou, B. H. Lipshutz, Green Chem. 2020, under review; b) M. Bihani, P. P. Bora, M. Nachtegaal, F. Gallou, S. Handa, ACS Catal. 2019, 9, 7520; c) B. S. Takale, R. R. Thakore, S. Handa, F. Gallou, J. Reilly, B. H. Lipshutz, Chem. Sci. 2019, 10, 8825; d) S. Handa, F. Ibrahim, T. Ansari, F. Gallou, ChemCatChem 2019, 9, 4229; e) N. R. Lee, M. Cortes-Clerget, A. B. Wood, D. J. Lippincott, H. Pang, F. Moghadam, F. Gallou, B. H. Lipshutz, Chem CatChem 2019, 12, 3159; f) E. B. Landstrom, S. Handa, D. H. Aue, F. Gallou, B. H. Lipshutz, Green Chem. 2018, 20, 3436; g) P. Guo, H. Zhang, J. Zhou, F. Gallou, M. Parmentier, H. Wang, J. Org. Chem. 2018, 83, 7523; h) N. A. Isley, Y. Wang, F. Gallou, S. Handa, D. H. Aue, B. H. Lipshutz, ACS Cat. 2017, 7, 8331; i) J. D. Smith, F. Gallou, S. Handa, Johnson Matthey Technol. Rev. 2017, 61, 231; j) S. Handa, M. P. Andersson, F. Gallou, J. Reilly, B. H. Lipshutz, Angew. Chem. Int. Ed. 2016, 55, 4914; k) S. Handa, Y. Wang, F. Gallou, B. H. Lipshutz, Science 2015, 349, 1087.

[24] a) Y. Zhang, B. S. Takale, F. Gallou, J. Reilly, B. H. Lipshutz, Chem. Sci. 2019, 10, 10556; b) R. Thakore, B. S. Takale, F. Gallou, J. Reilly, B. H. Lipshutz, ACS Catal. 2019, 9, 11647; c) T. Ansari, A. Taussat, A. Clark, M. Nachtegaal, S. Plummer, F Gallou, S. Handa, ACS Catal. 2019, 9, 10389.

[25] H. Pang, Y. Wang, F. Gallou, B. H. Lipshutz, J. Am. Chem. Soc. 2019, 43, 17117.

[26] M. Cortes-Clerget, N. Akporji, J. Zhou, F. Gao, P. Guo, M. Parmentier, F. Gallou, J.-Y. Berthon, B. H. Lipshutz, Nature Comm. 2019,10, 2169.

[27] a) P. P. Bora, M. B. Bihani, S. Plummer, F. Gallou, S. Handa, ChemSusChem 2019, 12, 3037; b) N. R. Lee, R. T. H. Linstadt, D. J. Gloisten, F. Gallou, B. H. Lipshutz, Org. Lett. 2018, 20, 2902; c) J. D. Smith, T. N. Ansari, M. P. Andersson, D. Yadagiri, F. Ibrahim, S. Liang, G. B. Hammond, F. Gallou, S. Handa, Green Chem. 2018, 20, 1784; d) D. J. Lippincott, P. J. Trejo-Soto, F. Gallou, B. H. Lipshutz, Org. Lett. 2018, 20, 5094; e) D. J. Lippincott, R. T. H. Linstadt, M. R. Maser, F. Gallou, B. H. Lipshutz, Org. Lett. 2018, 20 , 4719; f) U. T. Duong, A. Gade, S. Plummer, F. Gallou, S. Handa, ACS Catal. 2019, 9, 10963; g) H. Pang, Y. Wang, F. Gallou, B. H. Lipshutz, J. Am. Chem. Soc. 2018, 141, 17117
[28] S. Handa, M. P. Andersson, F. Gallou, J. Reilly, B. H. Lipshutz, Angew. Chem. Int. Ed. 2016, 55, 4914.

[29] E. B. Landstrom, S. Handa, D. H. Aue, F. Gallou, B. H. Lipshutz, Green Chem. 2018, 20, 3436

[30] a) D. P. Hruszkewycz, D. Balcells, L. M. Guard, N. Hazari, M. Tilset, J. Am. Chem. Soc. 2014, 136, 7300; b) A. J. deAngelis, P. G. Gildner, R. Chow, T. J. Colacot, J. Org. Chem. 2015, 80, 6794 .

[31] J. Bo, J. Reilly, F. Gallou, B. H. Lipshutz, Chem. Sci. 2019, 10, 3481.

[32] S. Wallace, E. P. Balskus, Angew. Chem. Int. Ed. 2016, 55, 6023.

[33] M. Cortes-Clerget, N. Akporji, J. Zhou, F. Gao, P. Guo, M. Parmentier, F. Gallou, J.-Y. Berthon, B. H. Lipshutz, Nat. Comm. 2019, 10, 2169.

[34] J. D. Smith, T. Ansari, M. P. Andersson, D. Yadagiri, F. Ibrahim, S. Liang, G. B. Hammond, F. Gallou, S. Handa, Green Chem. 2018, 20, 1784.

[35] N. K. Yee, I. N. Houpis, N. Haddad, R. Frutos, F. Gallou, X. Wang, X. Wei, R. D. Simpson, X. W. Feng, V. Fuchs, V. Xu, Y. Xu, J. Tan, L. Zhang, J. Xu, L. L. Smith-Keenan, J. Vitous, M. D. Ridges, E. M. Spinelli, M. Johnson, W. Samstag, K. Donsbach, T. Nicola, V. Farina, J. Org. Chem. 2006, 71, 7133.

[36] J. Brals, J. D. Smith, F. Ibrahim, F. Gallou, S. Handa, ACS Catal. 2017, 7, 7245 .

[37] a) S. Handa, F. Ibrahim, T. Ansari, F. Gallou, Chem CatChem 2019, 9, 4229; b) U. T. Duong, A. Gade, S. Plummer, F. Gallou, S. Handa, ACS Cat. 2019, 9, 10963.

[38] T. Ansari, A. Taussat, A. Clark, M. Nachtegaal, S. Plummer, F. Gallou, S. Handa, ACS Catal. 2019, 9, 10389.

[39] M. Bihani, P. P. Bora, M. Nachtegaal, F. Gallou, S. Handa, ACS Catal. 2019, 9, 7520 .

[40] a) C. E. Brocklehurst, F. Gallou, J. C. D. Hartwieg, M. Palmieri, D. Rufle, Org. Proc. Res. Dev. 2018, 22, 1453; b) B. S. Takale, R. R. Thakore, R. Mallarapu, F. Gallou, B. H. Lipshutz, Org. Proc. Res. Dev. 2020, accepted, doi.org/10.1021/acs.oprd.9b00455; c) D. J. Lippincott, E. Landstrom, M. Cortes-Clerget, B. H. Lipshutz, K. Buescher, R. Schreiber, C. Durano, M. Parmentier, N. Ye, B. Wu, M. Shi, H. Yang, M. Andersson, F. Gallou, Org. Proc. Res. Dev. 2020, accepted, doi.org/10.1021/acs.oprd.9b00454; d) T. N. Ansari, F. Gallou, S. Handa, 'Cross-couplings inWater - A BetterWay to Assemble New Bonds', in 'Organometallic Chemistry in Industry: A Practical Approach', 1st Ed., Wiley-VCH Verlag GmbH \& Co. KGaA, 2020 e) D. Kaldre, F. Gallou, C. Sparr, M. Parmentier, Chimia 2019, 73, 714.

\section{License and Terms}

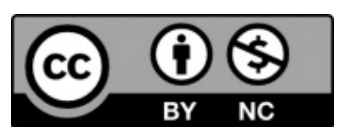

This is an Open Access article under the terms of the Creative Commons Attribution License CC BY_NC 4.0. The material may not be used for commercial purposes.

The license is subject to the CHIMIA terms and conditions: (http:// chimia.ch/component/sppagebuilder/?view=page $\& i d=12$ ).

The definitive version of this article is the electronic one that can be found at doi:10.2533/chimia.2020.538 